\title{
Our experience with pediatric surgical treatment of fibular hemimelia
}

\author{
A.M. Dzhuraev' ${ }^{1}$ B.U. Kholmatov², Kh.M. Karimov², A.R. Khashimov² \\ ${ }^{1}$ Republican Specialized Scientific and Practical Medical Center of Traumatology and Orthopedics \\ of the Ministry of Health of the Republic of Uzbekistan, Tashkent, Uzbekistan \\ ${ }^{2}$ Tashkent institute of postgraduate medical education, department of traumatology and orthopedics \\ of the Ministry of health of the Republic of Uzbekistan, Tashkent, Uzbekistan
}

\begin{abstract}
Introduction Fibular hemimelia is a rare congenital malformation of lower limbs with associated deformities of the knee and ankle joints. There is no consensus among the authors regarding the choice of treatment method, appropriate timing of surgery, strategy and postoperative rehabilitation. Objective To explore clinical manifestations of the deformities and review outcomes of pediatric surgical treatment of fibular hemimelia. Material and methods Surgical treatment was performed for 11 children with fibular hemimelia at the Department of Pediatric Orthopedics, RSSPMCTO RUz between 2014 and 2019. Clinical and instrumentation studies were produced for all patients. Results Outcomes of surgical treatment were evaluated using functional characteristics with 7 rated as good and 4 as fair. Conclusion External fixation offers an effective treatment option in the pediatric surgical management of fibular hemimelia.
\end{abstract}

Keywords: congenital malformation of tibia, fibular hemimelia, external fixation, surgical treatment, children

\section{INTRODUCTION}

Bone and joint malformations constitute 0.3 to $12.7 \%$ among congenital diseases. Congenital malformations may occur as an isolated malformation or may be associated with anomalies in other organ systems. Lower limb malformations are more common and they affect about $55 \%$ of children with congenital musculoskeletal disorders. Tibia is affected in 0.18 to $0.2 \%$ of the cases $[1,2]$. Musculoskeletal abnormalities are common among children with skeletal anomalies registered in $2.5 \%$ of livebirths $[3,4]$. Although most of congenital malformations of the limbs are not life threatening they can affect musculoskeletal development and result in impaired limb function and severe skeletal deformities. Congenital long bone deficiency is a rare congenital condition with an estimated incidence of 1 per 100 000 livebirths including a spectrum ranging from complete fibular aplasia to mild fibular hypoplasia with intact extension mechanism. Congenital long bone deficiency is often associated with deformities of the knee and ankle joints $[3,5,6]$.

Fibular hemimelia is the most common congenital long bone deficiency with the incidence of 7-15 per 1000000 livebirths [4]. Fibular hemimelia syndrome includes a wide range of disorders of the lower limbs with associated deformities of the femur, knee, tibia, ankle and foot. Clinical manifestations include shortening, flexion tibia alignment, valgus/ varus deformity of the knee, equinovarus deformity of the foot, flail knee joint and missing malleoli $[7,8]$. There is no consensus among the authors regarding the choice of treatment method, appropriate timing of surgery, strategy and postoperative rehabilitation. Many authors hypothesized about the best age for surgical treatment: from 5 month to 2 years, or from 3 years to 7 years. Amputation can be the best surgical option for patients with fibular aplasia with severely unstable ankle and considerable limb length discrepancy, whereas surgical limb reconstructions can be considered for the treatment of fibular deficiency using external fixation. Operative management of the condition is offered to produce with external fixation using either Ilizarov or VolkovOganesyan devices. However, external fixation devices used during intermediate or final stages of tibial reconstructions does not ensure good anatomical and functional outcome $[4,9,10,11]$. Objective To explore clinical manifestations of the deformities and review outcomes of pediatric surgical treatment of fibular hemimelia.

\section{MATERIAL AND METHODS}

Surgical treatment was performed for 11 children with fibular hemimelia at the Department of Pediatric Orthopedics, RSSPMCTO RUz between 2014 and
2019. The patients' age ranged between 2 and 12 years. Clinical and instrumentation studies produced for the patients revealed bilateral fibular hemimelia 
$(\mathrm{n}=3)$ and unilateral involvement $(\mathrm{n}=8)$. Physical examination typically showed reduced tibia volume, significantly atrophied soft tissues, claudication of different extent, limb length discrepancy of $3 \mathrm{~cm}$ to $10 \mathrm{~cm}$, missing $(\mathrm{n}=5)$ or hypoplastic $(\mathrm{n}=4)$ patella, valgus $(n=7)$, varus deformity $(n=2)$ and flexion contracture $(n=5)$. Tibia was hypoplastic $(n=11)$, deformed $(n=9)$ including tibial deformity in coronal plane $(n=2)$, sagittal $(n=3)$ and coronal and sagittal $(n=4)$ planes with the apex located in mid shaft in most cases. Severe changes were observed in the ankle and foot with missing lateral malleolus $(\mathrm{n}=11)$, underdeveloped and deformed foot $(\mathrm{n}=9)$, completely dislocated foot $(n=6)$ and equinovarus foot $(n=5)$.

\section{Clinical presentation}

A 3-year-old patient S.M. was seen by an orthopaedic surgeon who recommended conservative treatment at a regional hospital. The child could ambulate unassisted limping. He presented with fibular hemimelia having tibial deformity in the coronal and sagittal planes, valgus and flexion tibia alignment and a limb length discrepancy of $6 \mathrm{~cm}$. His tibia and femur muscles appeared to be atrophic, knee and ankle function impaired with valgus alignment, flexion contracture of the knee being moderate and the foot subluxed. Radiographic examination revealed missing fibula, hypoplastic articular surfaces of the knee and ankle joints, hypoplastic and curved tibia in the mid shaft at an angle being open posteriorly, underdeveloped ankle due to the absence of the lateral malleolus, lateral subluxation of the foot and defect of the $3 \mathrm{~d}$ and 4th toes on the right (Fig. 1) [4].

All patients underwent surgical treatment with use of external fixation. Two patients underwent a limb lengthening procedure only. The surgery was aimed at deformity correction and segment lengthening.

Treatment was performed in two stages. Tibia was lengthened and corrected and the ankle realigned using the Ilizarov fixator at the first stage. Frame assembly consisted of three rings and two half rings. A pair of crossing wires were placed at the distal femur and the proximal tibial metaphysis, and properly tensioned. Another two wires were driven in the distal tibial metaphysis, and a calcaneal wire and wire at the base of metatarsal bones were inserted and tensioned. Halfrings and full rings were connected with rods and hinges. Distractional epiphyseolysis produced during 4-7 postoperative days was followed by distraction at a rate of 1-2 mm per day for simultaneous limb lengthening and axial deformity correction during 2-3 months. The foot was concurrently realigned with distraction (Fig. 2). Drilling was performed at the apex of tibial deformity in cases of axial deformities measuring more than $20^{\circ}$ in children aged 5 years and over, and the bone was osteotomized at this level in children aged 10 years and over.

The period of fixation with the Ilizarov frame was dependent on severity of the deformity, age and amount of limb length discrepancy, and ranged between 3 to 6 months.

The second stage included creation of the ankle mortise with the foot transarticularly fixed with two $\mathrm{K}$-wires. The distal fibula and the talus were exposed for this purpose on the anteromedial aspect of the lower tibial third using sharp and blunt approach. Soft tissue bands were excised, and tibia was longitudinally dissected in the sagittal plane over $2 \mathrm{~cm}$ providing the distal bifurcation. The foot was transarticularly fixed at 85-95 ankle dorsiflexion using two K-wires placed in the heel for 3 to 4 weeks. The limb was additionally fixed with plaster cast from the groin to the toes. With foot wires removed the limb was casted for another 3 to 4 weeks and then the bandage was shortened to the proximal tibia to prevent contracture in the knee joint. Massage and physical therapy procedures were administered for the child after removal of the cast for strengthening lower limb muscles. The patient was recommended to use orthosis and orthopaedic footwear (Fig.3).

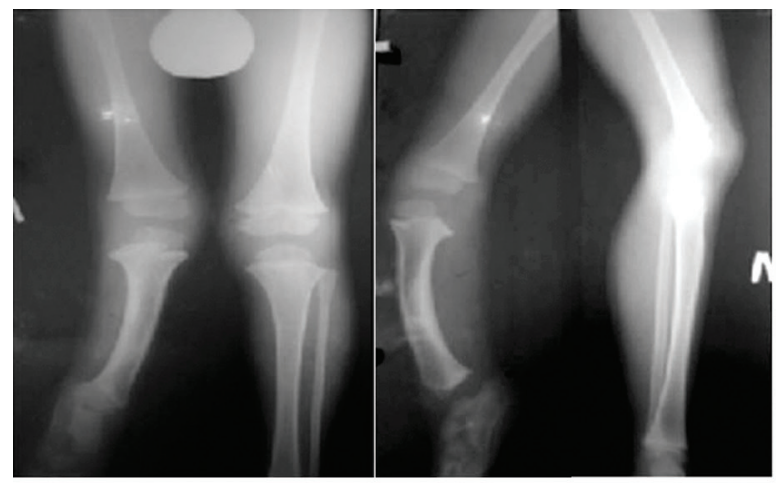

a

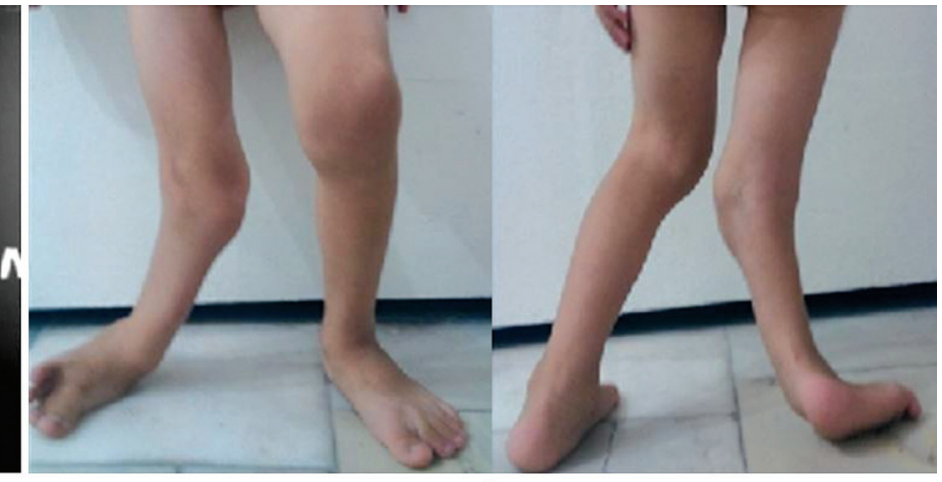

b

Fig. 1 A 3-year-old patient S.M. diagnosed with fibular hemimelia seen (a) radiologically on anteroposterior and lateral views and (b) clinically at the front and back views of lower limbs 
Genii Ortopedii, Vol. 26, no 4, 2020
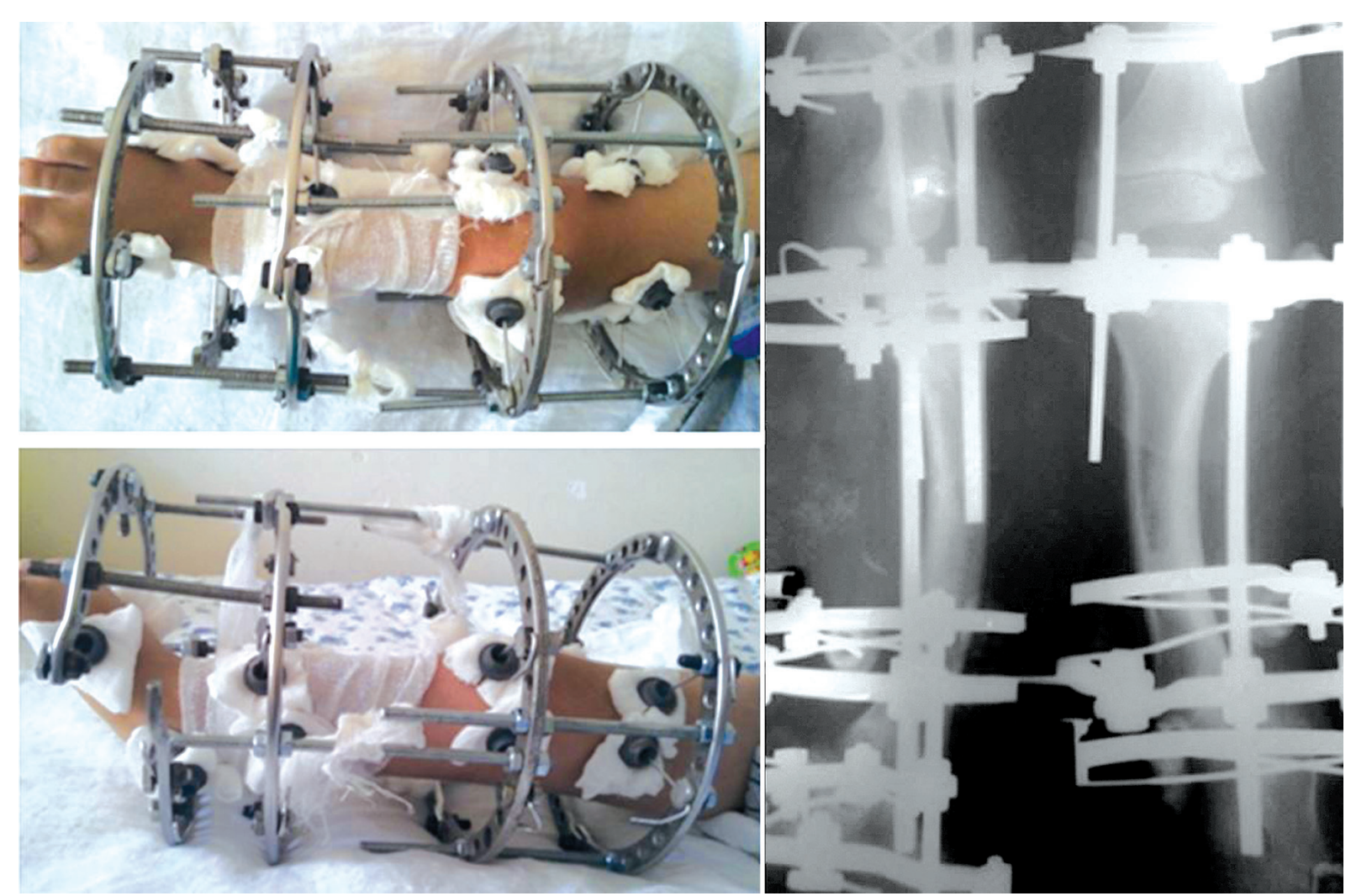

Fig. 2 Clinical appearance and radiographs of tibia of patient S.M. during surgical treatment with external fixation device
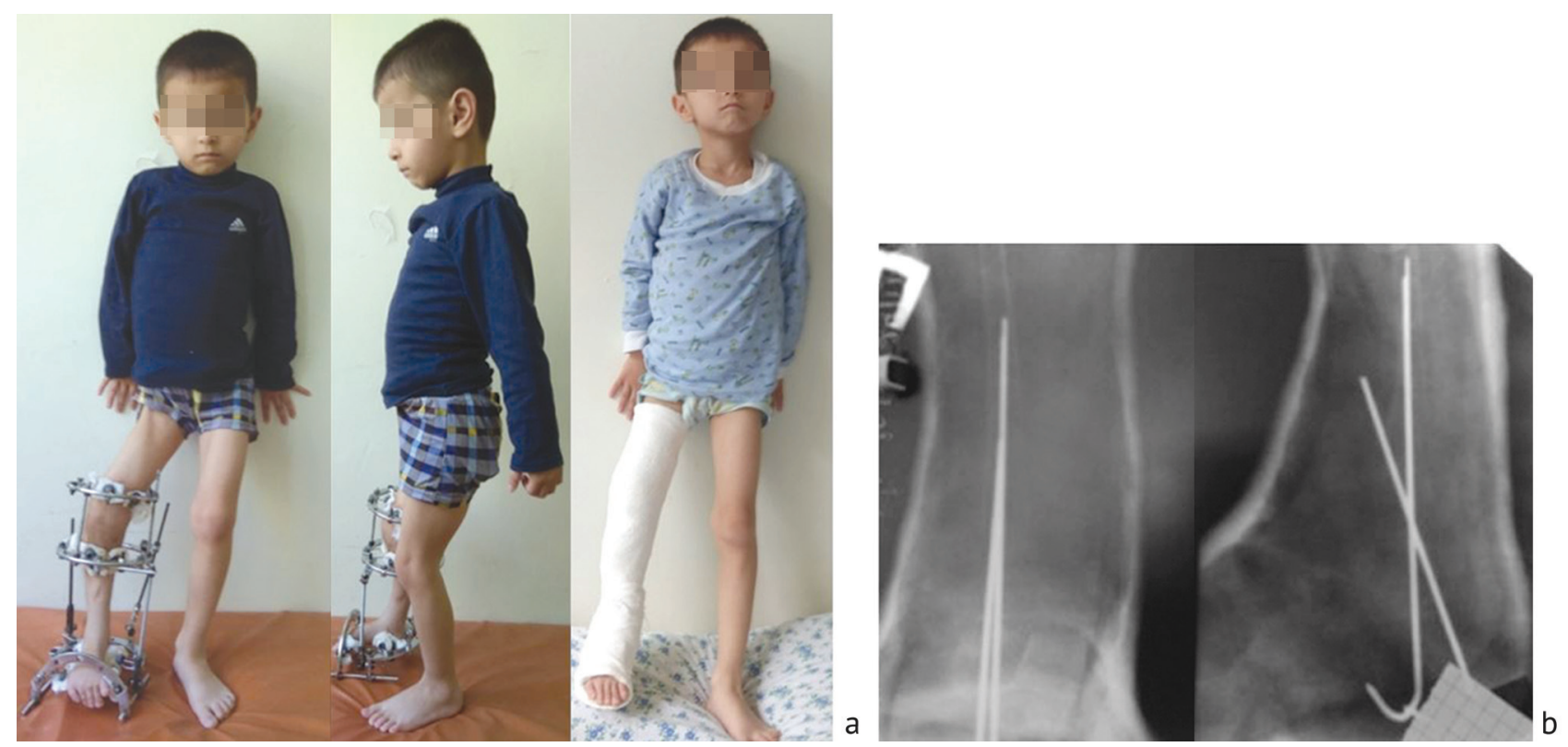

Fig. 3 Clinical appearance and radiographs of tibia of patient S.M. during treatment $(\boldsymbol{a})$ with tibiotalar articulation stabilized with wires $(\boldsymbol{b})$

\section{RESULTS}

Long-term outcomes of pediatric patients with fibular hemimelia were evaluated at one year with major stages of treatment being accomplished. The criteria evaluated included supportability of the leg, alignment of the lower limb, range of motion in the knee and ankle joints, limb length discrepancy and foot deformity, as well as the capability to ambulate unassisted. Outcomes were evaluated as good with completely regained supportability of the leg, unassisted ambulation, mild varus deformity, range of motion in the knee measuring at least $100^{\circ}$, stable ankle joint, reliable flexion and extension function, and mild planovalgus deformity of the foot. Outcomes were assessed as fair with regained supportability of the leg, unassisted ambulation, easier gait using orthosis, $3 \mathrm{~cm}$ shortening, varus/valgus malalignment (varus 
of not greater than $8^{\circ}$, valgus of not greater than $14^{\circ}$ ), range of motion in the knee measuring from $60^{\circ}$ to $80^{\circ}$ and $10^{\circ}$ to $20^{\circ}$ in the ankle joint. Among 11 pediatric patients, 7 outcomes were rated as good and 4 as fair.

\section{Clinical presentation}

A 7-year-old female patient was admitted to our hospital in 2015 presenting with deformity of the right lower limb and severe limping. The girl was diagnosed wih congenital anomaly of tibia, fibular hemimelia, equinovarus foot, and $6 \mathrm{~cm}$ shortening. In 2015 the patient was treated with the Ilizarov external fixator applied to the right lower limb to lengthen tibia. Four months later the surgery aimed at creation of tibiotalar articulation. Six-month follow-up showed good supportability of the right lower limb and limb length discrepncy of $2 \mathrm{~cm}$.
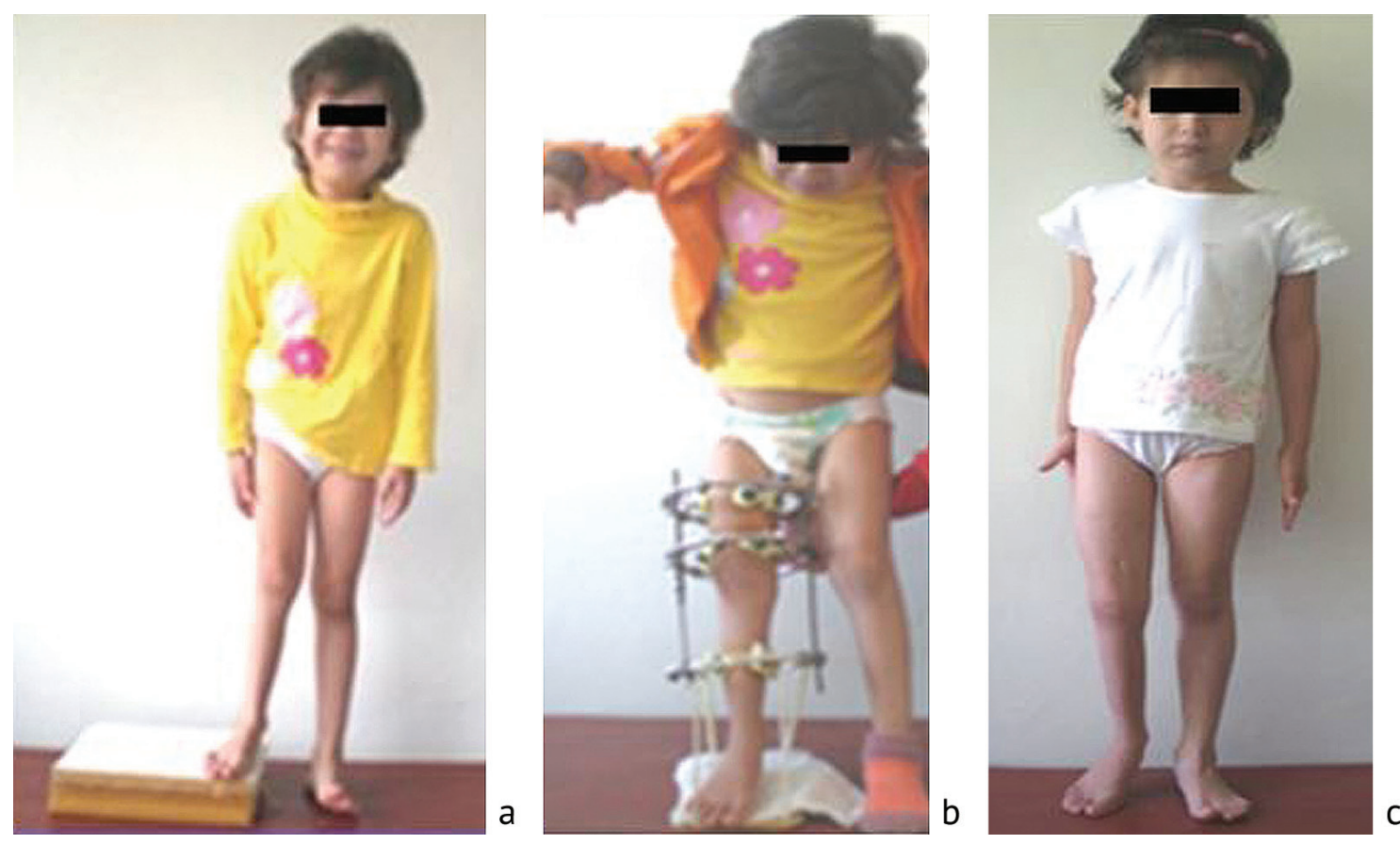

Fig. 4 Clinical appearance of a 7-year-old patient Kh. (a) before surgery; $(\boldsymbol{b})$ during treatment; $(\boldsymbol{c})$ after treatment

\section{DISCUSSION}

Fibular hemimelia is the most common congenital long bone deficiency and occurs more frequently than congenital anomalies of tibial bones. Bilateral fibular deficiency is more common and associated with foot deformities. There is no consensus among the authors regarding the choice of treatment method. There are two main possibilities when it comes to such matters: early amputation of the respective limb or a reconstructive procedure for limb salvage. For cases of complete absence of the fibula when the foot is nonfunctional, amputation may be considered to prevent multistaged surgical management that can be inefficient and associated with complications. Although amputation is an economically beneficial procedure it remains associated with high rate of adverse events and is an irreversible process. Prosthesis options and the ability to use certain prosthetic technologies can vary greatly between different countries $[9,12]$.

Less traumtic methods of extrafocal osteosynthesis have a unique role in orthopaedic surgery and pediatric patients can benefit from surgical interventions combined with the Ilizarov external fixation $[2,10]$. The Ilizarov method for severe limb length inequality and foot deformity in congenital fibula absence provides a relatively anatomical limb and good functional outcome.

We do not consider amputation as the treatment option because limb lengthening has been shown to be reliable and safe facilitating functional plantigrade foot. In that regards, efforts should be made to restore and save the lower limb in congenital fibula absence. We are unable to support Oppenheim's opinion that amputation can be indicated for limb length discrepancy of $7 \mathrm{~cm}$ and over in skeletally mature individuals and that surgical treatment fails to provide functional foot. Our findings showed that Ilizarov limb lengthening and reconstruction can offer a good treatment option for severe foot deformity in congenital fibula absence. Parental counselling regarding multistage long-term management, adverse events during correction is paramount in achieving the optimum functional outcome. 


\section{CONCLUSION}

External fixation offers an effective treatment option in the pediatric surgical management of fibular hemimelia. Early surgical management of fibular hemimelia is a reliable prophylaxis of complications associated with progression of joint contractures and lower limb deformities allowing to address soft tissue traction and retraction, bone malalignment and the relations. It also provides more favorable conditions for relatively adequate development of the lower limbs.

\section{REFERENCES}

1. Baindurashvili A.G., Karimova L.F. Vrozhdennye poroki razvitiia kostei goleni u detei: monografiia [Congenital malformations of the leg bone development in children: monograph]. St. Petersburg, SpetsLit, 2012, 204 p. (in Russian)

2. Vilenskii V.A., Zakharian E.A., Pozdeev A.A., Zubairov T.F., Pozdeev A.P. Lechenie detei s vrozhdennymi deformatsiiami dlinnykh kostei nizhnikh konechnostei putem posledovatelnogo ispolzovaniia upravliaemogo rosta i chreskostnogo osteosinteza (predvaritelnoe soobshchenie) [Treatment of children with congenital deformities of the lower limb long bones through successive using guided growth and transosseous osteosynthesis (preliminary report)]. Ortopediia, Travmatologiia i Vosstanovitelnaia Khirurgiia Detskogo Vozrasta, 2018, vol. 6, issue 3, pp. 12-24. (in Russian)

3. Dedukh N.V., Khmyzov S.A., Podlipentsev V.V., Tikhonenko A.A. Vrozhdennye anomalii konechnostei (obzor literatury) [Congenital anomalies of limbs (review of the literature)]. Ortopediia, Travmatologiia i Protezirovanie, 2013, no. 2, pp. 102-108. (in Russian)

4. Paley D. Radiographic assessment of lower limb deformities. Principles of Deformity Correction. $1^{\text {st }}$ Ed. Berlin, Heidelberg, Springer-Verlag, 2002, chapter 3, pp. 31-60.

5. Shevtsov V.I., Aranovich A.M., Makushin V.D., Chegurov O.K. Klassifikatsiia prodolnoi ektromelii goleni [Classification of the longitudinal ectromelia of the leg]. Genij Ortopedii, 2005, no. 4, pp. 92-97. (in Russian)

6. Bergère A., Amzallag-Bellenger E., Lefebvre G., Dieux-Coeslier A., Mezel A., Herbaux B., Boutry N. Imaging features of lower limb malformations above the foot. Diagn. Interv. Imaging, 2015, vol. 96, no. 9, pp. 901-914. DOI: 10.1016/j.diii.2014.08.008

7. Shevtsov V.I., Aranovich A.M., Makushin V.D., Chegurov O.K. Khirurgicheskoe lechenie vrozhdennykh anomalii razvitiia bertsovykh kostei [Surgical Treatment of congenital anomalies of leg bones]. Kurgan, 1998, 324 p. (in Russian)

8. Aouni S., Bigot J., Petit S., Dieux-Coeslier A., Herbaux B., Gabor F., Cagneaux M., Boutry N. Apport du scanner spiralé audiagnostic prénatal d'une forme sévère d'hémimélie fibulaire [Prenatal helical CT diagnosis of severe fibular hemimelia]. J. Radiol., 2011, vol. 92, no. 5, pp. 431-436. (in French) DOI: 10.1016/j.jradio.2011.03.004

9. Alessandri J.L., Isidor B., David A., Martin-Coignard D., Ghazouani J., Ramful D., Laville J.M., Le Caignec C. Tibial developmental field defect in valproic acid embryopathy: Report on three cases. Am. J. Med. Genet. A, 2010, vol. 152A, no. 11, pp. 2805-2809. DOI: 10.1002/ajmg.a.33633

10. Bonnard C., Favard L., Sollogoub I., Glorion B. Limb lengthening in children using the Ilizarov method. Clin. Orthop. Relat. Res., 1993, no. 293, pp. $83-88$

11. El-Sayed M.M., Correll J., Pohlig K. Limb sparing reconstructive surgery and Ilizarov lengthening in fibular hemimelia of Achterman-Kalamchi type II patients. J. Pediat. Orthop. B, 2010, vol. 19, no. 1, pp. 55-60. DOI: 10.1097/BPB.0b013e32832f5ace

12. Courvoisier A., Sailhan F., Thevenin-Lemoine C., Vialle R., Damsin J.-P. Congenital tibial deficiencies: treatment using the Ilizarov's external fixator. Orthop. Traumatol. Surg. Res., 2009, vol. 95, no. 6, pp. 431-436. DOI: 10.1016/j.otsr.2009.04.017

Received: 07.02.2020

\section{Information about the authors:}

1. Akhror M. Dzhuraev, M.D., Ph.D., Professor, Republican Specialized Scientific and Practical Medical Center of Traumatology and Orthopedics, Tashkent, Uzbekistan, Email: axrorbek@mail.ru

2. Botir U. Kholmatov, M.D., Tashkent Institute of Postgraduate Medical Education, Tashkent, Uzbekistan, Email: Botirboy955@gmail.com

3. Khotam M. Karimov, M.D., Ph.D., Tashkent Institute of Postgraduate Medical Education, Tashkent, Uzbekistan, Email: Trav-ort@rambler.ru

4. Abdurasul R. Hashimov, M.D., Ph.D., Tashkent Institute of Postgraduate Medical Education, Tashkent, Uzbekistan Email: Xashimov9091@gmail.com 